\title{
Factors influencing hand hygiene compliance of healthcare students
}

\author{
Salah H Elsafi ${ }^{1}$, Shahad Y Al-Howti \\ ${ }^{1}$ Clinical Laboratory Science Department, Prince Sultan Military College of Health Sciences, \\ Dammam, Saudi Arabia. \\ ${ }^{2}$ Point of Care Testing, Central Military Laboratory and Blood Bank, \\ Prince Sultan Military Medical City, Riyadh, Saudi Arabia
}

doi: 10.3396/ijic.v15i4.015.19

\begin{abstract}
Hand hygiene is the most effective way to control healthcare-associated infections. The aim of this study is to measure the hand hygiene awareness and practices in relation to various variables among the healthcare students. A structured validated questionnaire was completed by the participants to assess their awareness and compliance with hand hygiene. The average knowledge score of 500 students was $6.24 / 10$ with a significant difference between various departments $(p=0.001)$. Knowledge significantly increased by advanced years of study. The average attitude and practice scores were 6.96 and 5.13 , respectively with significant differences only in practice between various departments but not within other variables. Despite an overall good knowledge and attitude, the compliance of hand hygiene was generally poor. These findings suggested that other factors than knowledge and attitude might play a role in compliance. Although there appears to be a direct correlation with knowledge and year of study (Correlation coefficient $r=0.96)$ a weaker correlation value was detected with attitude $(r=0.02)$. Conversely, we detected a negative correlation between compliance with hand hygiene and the year of study $(r=$ -0.55). In contrast to many other studies, no gender difference in attitude and practice in this study.
\end{abstract}

Keywords: Hand hygiene, knowledge, compliance, students, Saudi Arabia

\section{Corresponding Author}

Salah H Elsafi

Chairman, Clinical Laboratory Science Department, Prince Sultan Military College of Health Sciences,

P. O. Box 33048, Dammam 31448, Saudi Arabia.

E-mail: salahelsafi@hotmail.com 


\section{Background}

Health care-associated infections (HCAls) are of paramount interest worldwide. It has been estimated that about $4 \%$ of the acute care hospitalisations had one or more HCAls. ${ }^{1}$ In developed countries, HCAls affect $5-15 \%$ of hospitalised patients and can affect 9-37\% of those admitted to intensive care units. ${ }^{2} \mathrm{~A}$ number of strategies have been proposed to minimize the occurrence of HCAls, including environmental management, physical barriers, hand hygiene, and the use of biosensors. ${ }^{3}$ Several studies have examined the links between hand hygiene compliance of health care workers and HCAl rates. ${ }^{4}$ Hand hygiene is considered the most effective part of any effort to control HCAls. ${ }^{5}$ Unfortunately, adherence to hand hygiene guidelines is often suboptimal in health care workers. ${ }^{6}$

Medical and allied health science students, as future health care providers, are often thought to play an important role in the prevention of HCAls. Despite all the efforts made in the field of hand hygiene and the use of various methods to improve it, results of other studies suggest low levels of hand hygiene among health care students. ${ }^{7}$ Compliance with hand hygiene varies based on hospital, department and working conditions. $^{8}$

Hand hygiene compliance is affected by several factors including the personal knowledge of hand hygiene, perception of the benefits, professional background, gender, infectious disease severity, work intensity and presence of facilities. ${ }^{9}$ Identification of such factors helps to improve compliance with hand hygiene behaviours.

Information about the knowledge, attitude and performance of hand hygiene is necessary as it identifies and assesses the barriers against compliance. Barriers against the compliance of hand hygiene occur with a person's negative attitude which may be due to lack of knowledge. Studies that investigated the knowledge and attitude of healthcare workers towards hand hygiene have shown a wide variation within various communities. ${ }^{7-9}$ Although there has been considerable research on the hand hygiene knowledge, beliefs, and compliance of medical and nursing students, only a few studies were done on other healthcare students. Moreover, little research has been conducted to determine if differences between the professions in relation to hand hygiene are apparent at the undergraduate level.

The aim of this study was to examine allied health sciences students' hand hygiene awareness and practices in relation to various variables that exist between various majors, years of study, and gender in the undergraduate setting. Information from this study will be used to inform undergraduate curriculum developers. In addition, determining the factors affecting hand-hygiene compliance in health sciences students provides a chance to address any gaps in knowledge and practices before the students graduate and enter the medical community.

\section{Material and methods}

This cross-sectional study was conducted among the students of the Prince Sultan Military College of Health Sciences (PSMCHS), Dhahran, during September 2015 to August 2016. The PSMCHS is an allied health college with approximately 1,100 students. The study plan of the College consists of one year of preclinical studies followed by 3 years of clinical studies in one of the various departments that include Nursing, Clinical Laboratory Sciences (CLS), Respiratory Care (RC), Anaesthesia, Emergency Medical Technology (EMT), and Dental and Oral Health (DOH).

This study was approved by the ethics committee of the Prince Sultan Military Medical College of Health Sciences. The desired size of the sample was chosen using a stratified random sample to get representation of all departments. A total of 500 students, representing $45.5 \%$ of the college students were selected.

A well-structured, validated and pre-tested questionnaire was designed according to the study's objectives. ${ }^{10}$ The questionnaire was developed based on related literature ${ }^{9,11-12}$ and consisted of 25 questions. The first part of the questionnaire contained demographic information such as age, gender, class level, field of study, and the grade point average (GPA). The second part was designed to assess knowledge using a modified World Health Organization hand hygiene questionnaire for health care workers, ${ }^{12}$ consisting of 10 multiple choice 
questions with four choices that included one correct answer. In the third part, the students were also asked about their beliefs and attitudes towards hand hygiene using five questions on a five-point Likert scale. The last part examined students' hand hygiene practice, which was self-reported by the respondents through answering questions about where, when and how hand hygiene is practiced.

Questions were validated by a panel of experts, including microbiology consultants, infection control committee members, and statisticians of PSMCHS, before conducting a pilot test involving 20 students who were not included in the study. Data collected from the pilot test were then tested for the internal consistency of the questionnaire by using SPSS, which revealed a reliable coefficient (Cronbach's alpha) of 0.86 .

A briefing was given to the participants about the objectives of the study and they were assured of the confidentiality of their personal data. A written informed consent was signed by every participant. The anonymised questionnaires were filled in by the participants in the presence of the researchers. Only when an illegible answer to the questionnaire was encountered at the time of submission, the respondents were asked by the researchers for clarification.

\section{Statistical analysis}

The results were analyzed and tested for statistical significance, when required, with the use of SPSS (IBM Corp. Released 2011. IBM SPSS Statistics for Windows, Version 20.0. Armonk, NY: IBM Corp.). The scoring of knowledge consisted of 10 multiple choice questions with four distractors. A score "1" was given for each correct answer and a zero score was given for each wrong answer. Answers to part three questions were measured in the form of a 5-point Likert scale rating ranging from "strongly disagree" $=$ "1", to "strongly agree" = " 5 ". Then the score was calculated out of 10 for the five questions of the 5 -point Likert scale. Differences in distribution were

Table I. Average scores (out of 10 on items of the hand hygiene knowledge with the $95 \%$ confidence interval (Cl)

\begin{tabular}{llrrrr} 
& Variable & $\mathbf{n}$ & \pm SD & $95 \% \mathbf{C l}$ & $\mathbf{p}$ \\
\hline Gender & Male & 269 & $6.20 \pm 1.69$ & $6.00-6.40$ & 0.460 \\
& Female & 231 & $6.30 \pm 1.34$ & $6.13-6.47$ & \\
\hline Department & CLS & 113 & $6.55 \pm 1.55$ & $6.26-6.84$ & \\
& RC & 75 & $7.09 \pm 1.42$ & $6.77-7.42$ & \\
& Anaesthesia & 63 & $6.03 \pm 1.75$ & $5.59-6.47$ & \\
& Nursing & 59 & $6.83 \pm 1.23$ & $6.51-7.15$ & 0.001 \\
& DOH & 56 & $5.9 \pm 1.52$ & $5.52-6.34$ & \\
& EMT & 134 & $5.49 \pm 1.17$ & $5.28-5.69$ & \\
\hline Year & Preclinical & 138 & $5.49 \pm 1.17$ & $5.30-5.69$ & \\
& $1^{\text {st }}$ year & 107 & $6.52 \pm 1.59$ & $6.22-6.83$ & \\
& $2^{\text {nd }}$ year & 114 & $6.42 \pm 1.63$ & $6.12-6.72$ & 0.001 \\
& $3^{\text {rd }}$ year & 95 & $6.45 \pm 1.60$ & $6.13-6.78$ & \\
& $4^{\text {th }}$ year & 46 & $6.98 \pm 1.18$ & $6.63-7.33$ & \\
\hline GPA & $4-5$ & 334 & $6.22 \pm 1.46$ & $6.06-6.38$ & 0.010 \\
& $3-4$ & 138 & $6.28 \pm 1.66$ & $6.00-6.56$ & \\
\hline Total & $<3$ & 28 & $6.36 \pm 1.94$ & $5.64-7.07$ & \\
\hline & & 500 & $6.24 \pm 1.54$ & $6.11-6.38$ &
\end{tabular}


Table II. Average scores (out of 10 on items of the hand hygiene beliefs scale with the $95 \%$ confidence interval (Cl)

\begin{tabular}{llrrrr} 
& Gender & $\mathbf{n}$ & \pm SD & $95 \%$ Cl & p \\
\hline Gender & Male & 269 & $7.02 \pm 1.40$ & $6.85-7.18$ & 0.290 \\
& Female & 231 & $6.89 \pm 1.25$ & $6.73-7.05$ & \\
\hline Department & CLS & 113 & $6.88 \pm 1.48$ & $6.60-7.15$ & \\
& RC & 75 & $7.12 \pm 1.25$ & $6.82-7.40$ & 0.202 \\
& Anaesthesia & 63 & $7.15 \pm 1.41$ & $6.79-7.50$ & \\
& Nursing & 59 & $6.88 \pm 1.35$ & $6.53-7.23$ & \\
& DOH & 56 & $7.21 \pm 1.20$ & $6.88-7.52$ & \\
& EMT & 134 & $6.78 \pm 1.24$ & $6.56-6.98$ & \\
\hline Year & Preclinical & 138 & $6.77 \pm 1.23$ & $6.56-6.97$ & \\
& $1^{\text {st }}$ year & 107 & $6.96 \pm 1.38$ & $6.69-7.22$ & \\
& $2^{\text {nd }}$ year & 114 & $7.34 \pm 1.34$ & $7.08-7.58$ & 0.010 \\
& $3^{\text {rd }}$ year & 95 & $6.83 \pm 1.40$ & $6.54-7.11$ & \\
& $4^{\text {th }}$ year & 46 & $6.86 \pm 1.21$ & $6.50-7.21$ & \\
\hline GPA & $4-5$ & 334 & $6.93 \pm 1.26$ & $6.79-7.06$ & \\
& $3-4$ & 138 & $7.09 \pm 1.34$ & $6.86-7.31$ & 0.261 \\
& $<3$ & 28 & $6.68 \pm 1.99$ & $5.90-7.45$ & \\
\hline Total & & 500 & $6.96 \pm 1.33$ & $6.84-7.07$ &
\end{tabular}

tested with the use of the ANOVA $F$-test standard error and the $95 \%$ confidence interval for the mean. The scoring of practice also consisted of 10 multiple choice questions with four distractors. A score "1" was given for each correct answer and a zero score was given for each wrong answer.

We calculated the correlation coefficient to measure the strength of the relationship between different variables by using the Pearson product-moment correlation coefficient (PMCC). The statistical significance was set at $p>0.05$ for all analyses.

\section{Results}

In total 500 students were enrolled in the study, 269 of which (53.8\%) were males. These were from different departments as follows: 113 belonged to the Clinical Laboratory Science (CLS), 75 to Respiratory Care (RC), 63 to Anaesthesia, 59 to Nursing, 56 to Dental and Oral Health (DOH), and 134 to Emergency Medicine Technology (EMT). Of the all students, $27.6 \%$ ( $n=$ $138)$ were in their preclinical year, $21.4 \%(n=107)$ were in their first year, $22.8 \%(n=114)$ were in their second year, $19 \%(n=95)$ were in their third year and $19 \%(n=46)$ in their fourth year.

The average knowledge score was 6.24 out of 10 with a significant difference between various departments (Table I). The highest knowledge score was 7.09 reported by the RC department while the lowest was 5.49 reported by the EMT department. Knowledge significantly increased by advanced years of study. No variation was detected due to the student's mean grade point average (GPA) and gender.

The average attitude score was 6.96 out of 10 with no significant differences between genders, various departments, years of study, or GPA (Table II). The average practice score was 5.13 out of 10 . The highest practice score was 5.73 reported by the Anaesthesia department while the least was 4.61 reported by the Nursing department (Table III). Practice scores indicated no significant variation between departments, year of the study, or grade point average. 
Table III. Average score (out of 10 on items of the modified hand hygiene practices scale with the $95 \%$ confidence interval (Cl)

\begin{tabular}{|c|c|c|c|c|c|}
\hline & Gender & $\mathrm{n}$ & \pm SD & $95 \% \mathrm{Cl}$ & $\mathbf{P}$ \\
\hline \multirow[t]{2}{*}{ Gender } & Male & 269 & $5.29 \pm 1.87$ & $5.06-5.51$ & 0.074 \\
\hline & Female & 231 & $5.01 \pm 1.48$ & $4.82-5.20$ & \\
\hline \multirow[t]{6}{*}{ Department } & CLS & 113 & $5.37 \pm 1.86$ & $5.02-5.72$ & 0.010 \\
\hline & $\mathrm{RC}$ & 75 & $4.81 \pm 1.51$ & $4.47-5.16$ & \\
\hline & Anaesthesia & 63 & $5.73 \pm 1.80$ & $5.28-6.18$ & \\
\hline & Nursing & 59 & $4.61 \pm 1.26$ & $4.28-4.94$ & \\
\hline & $\mathrm{DOH}$ & 56 & $5.39 \pm 1.73$ & $4.93-5.86$ & \\
\hline & EMT & 134 & $5.05 \pm 1.68$ & $4.77-5.34$ & \\
\hline \multirow[t]{5}{*}{ Year } & Preclinical & 138 & $5.09 \pm 1.68$ & $4.81-5.38$ & 0.437 \\
\hline & $1^{\text {st }}$ year & 107 & $5.26 \pm 1.51$ & $4.97-5.55$ & \\
\hline & $2^{\text {nd }}$ year & 114 & $5.29 \pm 1.79$ & $4.96-5.62$ & \\
\hline & $3^{\text {rd }}$ year & 95 & $5.18 \pm 1.97$ & $4.78-5.58$ & \\
\hline & $4^{\text {th }}$ year & 46 & $4.76 \pm 1.34$ & $4.36-5.16$ & \\
\hline \multirow[t]{3}{*}{ GPA } & $4-5$ & 334 & $5.06 \pm 1.68$ & $4.88-5.24$ & 0.010 \\
\hline & $3-4$ & 138 & $5.28 \pm 1.70$ & $5.00-5.57$ & \\
\hline & $<3$ & 28 & $5.71 \pm 1.94$ & 4.96-6.47 & \\
\hline Total & & 500 & $5.13 \pm 1.70$ & $5.01-5.31$ & \\
\hline
\end{tabular}

\section{Discussion}

Hand hygiene knowledge questions included source and route of cross-transmission of pathogens, practice associated with increased likelihood of colonisation of hands, when and how to practice hand hygiene, and the different methods of hand hygiene. The overall average knowledge score in the present study was good when compared to other studies, with a significant variation among different majors..$^{7-9}$ The highest knowledge was demonstrated by the Anaesthesia and RT departments while the lowest one was shown by the EMT department.

Despite the overall good knowledge and attitude, the compliance with hand hygiene in practice was generally poor among all groups. These findings suggested that factors other than knowledge and attitude might play a role in compliance. There are several self-reported factors for poor adherence with hand hygiene that included irritation and dryness, lack of facilities, lack of time, beliefs that glove use obviates the need for hand hygiene, and lack of experience. $^{12}$
This study has shown a marked statistically significant link between the field of study and hand hygiene knowledge and practice. Anaesthesia students have shown the best compliance with hand hygiene guidelines followed by Dental and Oral Health and Clinical Laboratory Science students, while Nursing students were the least compliant. This may indicate that the taught material on hand hygiene and its importance is influencing a students' hygiene behaviour.

Information provided in the classroom may lead to a better understanding and a greater appreciation for the need to wash hands when practicing the profession.

It has been reported that the type of health care worker and their workload are major determinants for non-compliance with hand hygiene in the health care setting. ${ }^{7}$

Adherence rates to hand hygiene in this study have shown a significant variation between different 
majors. This rate of compliance is low compared to other findings. ${ }^{7-9}$ It has been found that the use of any form of hand hygiene related to patient encounters in the ICU was much higher than others. A further study has also shown that the highest adherence rate to hand hygiene of $72.6 \%$ was observed among respiratory therapists. ${ }^{13}$

The present study has shown that the mean hand hygiene scores among student nurses were 68.8, 68.8 and 46.1 for knowledge, belief, and practice respectively. Nurse student's knowledge and compliance has been studied widely. In one study the mean hand hygiene scores among student nurses were found to be $34.26 / 40,86.39 / 115$ and $64.52 / 70$ for knowledge, belief, and practice respectively. ${ }^{14}$ This study also has shown that the mean hand hygiene scores among dental students were 5.90, 7.21 and 5.39 out of 10 for knowledge, belief, and practice respectively. In one study among dental students the average knowledge score was 4.2 out of 10 while the attitude and practice scores were represented by 10.2 out of 12 and 5.4 out of 6 , respectively. ${ }^{15}$ In this study, clinical laboratory science students have demonstrated a better compliance with hand hygiene. It has been reported before that the level of compliance of hand hygiene among laboratory personnel at the end of duty was $100 \% .{ }^{16}$ The present study has shown that the mean hand hygiene scores among Emergency Medicine Technology students were $5.49,6.78$ and 5.05 out of 10 for knowledge, belief, and practice respectively. The poor compliance rate among Emergency Medical Service workers has been reported before with rates ranging from $6 \%$ to $66 \%{ }^{17}$

Although there appears to be a direct correlation with knowledge and years of study (Correlation coefficient $r=0.96)$ a weaker correlation value was detected with attitude $(r=0.02)$. Conversely, we have detected a negative correlation between compliance with hand hygiene and years of study $(r=-0.55)$. Since the guidelines on hand hygiene is early during the first year of the study, this finding might indicate that repeated instructions on the same topic is necessary for improving hand hygiene compliance. This finding has also been noticed in another study were compliance to hand hygiene decreases from the first to sixth year medical students which was ascribed to a change in social and moral norms. ${ }^{18}$

Knowledge and attitude differences were observed significantly more often in the fourth year of study compared to the preceding years. There appears to be a direct correlation with compliance when compared with the year of study. We demonstrated an improvement in hand hygiene performance immediately after the first year through the fourth year of studies not only in knowledge, but also attitude.

In contrast to many other studies that indicated that females are more likely to wash their hands than males, ${ }^{11}, 20-21$ we found no gender difference in attitude and practice in this study.

No variation was detected due to the student's GPA and gender. Students with lower GPA have consistently demonstrated better knowledge, attitude, and compliance with hand hygiene.

We correlated the relationship between knowledge, attitude, and practice by using the Pearson productmoment correlation coefficient (PMCC). This test indicated a positive moderate correlation between the overall participants' attitudes and their compliance with hand hygiene (PMCC $=0.42$ ). Although there was a weak correlation between knowledge and attitude (PMCC $=0.12$ ), we found a moderate negative correlation between knowledge and practice (PMCC $=-0.53)$.

However, the importance of early and repeated education in the field of infection control in general and hand hygiene compliance in particular has been widely demonstrated..$^{21}$ Lack of knowledge about the right time point to disinfect hands, a lack of positive role models and simply the accessibility of hand rub solutions were all found to play a role in lack of compliance to hand hygiene by physicians. It is therefore unsurprising that there has been a growing consensus urging the implementation of more and more training about hand hygiene for both medics and other hospital staff. ${ }^{21}$ Other studies have found that an increase in the understanding of the benefits of hand hygiene increases the likelihood of hand washing. ${ }^{22-24}$ 
Failure to wash hands was attributed to forgetting, being too busy, lack of resources and sore hands. ${ }^{30}$ Several factors are likely to contribute to poor hand hygiene practices, including inadequate awareness of the issue, personal concerns such as skin irritation and dryness from frequent washing, availability of hand-washing solutions, or time constraints.

We suggest implementing regular training on hand hygiene early on during medical studies as one of the first steps to improving quality of patient care by reducing healthcare-associated infections. Such a training need was also highlighted by a recent report that has demonstrated that medical students in general have less knowledge about hand hygiene guidelines and standard precautions compared to nursing students. ${ }^{25}$

\section{Acknowledgments}

This work received no financial support. The authors report no conflicts of interest in this work. We thank all participants for their valuable cooperation. Thanks are also due to $\mathrm{Mr}$ Arulanantham Z Jebakumar for helping in the statistical analysis and Mr Louis Greenwood for reading the manuscript.

\section{References}

1. Magill SS, Edwards JR, Bamberg W, et al. Emerging infections program healthcare-associated infections and antimicrobial use prevalence survey team. Multistate point prevalence survey of health care-associated infections. N EngI J Med 2014; 370: 1198-1208. https://doi.org/10.1056/NEJMoa1306801

2. Lopez AD, Mathers CD, Ezzati M, Jamison DT, Murray CJ. Global and regional burden of disease and risk factors, 2001: systematic analysis of population health data. Lancet 2006; 367: 1747-1757. https://doi.org/10.1016/S01406736(06)68770-9

3. Schmier JK, Hulme-Lowe CK, Semenova S, et al. Estimated hospital costs associated with preventable health careassociated infections if health care antiseptic products were unavailable. Clinicoecon Outcomes Res 2016; 8: 197-205. https://doi.org/10.2147/CEOR.S102505

4. Morgan DJ, Kaye KS, Diekema DJ. Reconsidering isolation precautions for endemic methicillin-resistant Staphylococcus aureus and vancomycin-resistant Enterococcus. JAMA 2014; 312: 1395-1396. https://doi.org/10.1001/jama.2014.10142

5. Ellingson K, Haas JP, Aiello AE, et al. Society for Healthcare Epidemiology of America (SHEA). Strategies to prevent healthcare associated infections through hand hygiene. Infect Control Hosp Epidemiol 2014; 35: 937-960. https://doi. org/10.1086/651677
6. Allegranzi B, Conway L, Larson E, Pittet D. Status of the implementation of the World Health Organization multimodal hand hygiene strategy in United States of America health care facilities. Am J Infect Control 2014; 42: 224-230. https://doi. org/10.1016/j.ajic.2013.11.015

7. Limper HM, Barton G, McGinty M, et al. Behavioral intention of physician trainees and medical students to practice hand hygiene. Infect Control Hosp Epidemiol 2013; 34: 1102-1105. https://doi.org/10.1086/673146

8. Kowitt B, Jefferson J, Mermel LA. Factors associated with hand hygiene compliance at a tertiary care teaching hospital. Infect Control Hosp Epidemiol 2013; 34: 1146-1152. https:// doi.org/10.1086/673465

9. van de Mortel TF, Apostolopoulou E, Petrikkos G. A comparison of the hand hygiene knowledge, beliefs, and practices of Greek nursing and medical students. Am J Infect Control 2010; 38: 75-77. https://doi.org/10.1016/j. ajic.2009.05.006

10. van de Mortel T. Development of a questionnaire to assess health care students' hand hygiene knowledge, beliefs and practices. Australian J Adv Nurs 2009; 26: 9-16.

11. van de Mortel T, Bourke R, McLoughlin J, Nonu M, Reis M. Gender influences handwashing rates in the critical care unit. Am J Infect Control 2001; 29: 395-399. https://doi. org/10.1067/mic.2001.119511

12. Word Health Organization 2009. WHO guidelines on hand hygiene in health care: a summary. First global patient safety challenge clean care is safer care. World Helth Organization, Geneva. http://www.who.int/gpsc/5may/tools/who guidelines-handhygiene_summary.pdf (accessed July 4, 2019)

13. Qushmaq IA, Heels-Ansdell D, Cook DJ, Loeb MB, Meade MO. Hand hygiene in the intensive care unit: prospective observations of clinical practice. Pol Arch Med Wewn 2008; 118: 543-547. https://doi.org/10.20452/pamw.484

14. Karadag M, Iseri OP, Yildirim N, Etikan I. Knowledge, beliefs and practices of nurses and nursing students for hand hygiene. Jundishapur J Health Sci 2016; 8: e36469. https:// doi.org/10.17795/jjhs-36469

15. Yaembut N, Ampornaramveth P, Pisarnturakit PP, Subbalekha K. Dental student hand hygiene decreased with increased clinical experience. J Surg Educ 2016; 73: 400-408. https:// doi.org/10.1016/j.jsurg.2015.12.007

16. Alp E, Haverkate D, Voss A. Hand hygiene among laboratory workers. Infect Control Hosp Epidemiol 2006; 27: 978-980. https://doi.org/10.1086/506404

17. Ho JD, Ansari RK, Page D. Hand sanitization rates in an urban emergency medical services system. J Emerg Med 2014; 47: 163-168. https://doi.org/10.1016/j.jemermed.2013.08.070

18. Roberto MS, Mearns K, Silva SA. Social and moral norm differences among Portuguese 1st and 6th year medical students towards their intention to comply with hand hygiene. Psychol Health Med 2011; 17: 408-416. https://doi. org/10.1080/13548506.2011.626431

19. Anderson JL, Warren CA, Perez E, et al. Gender and ethnic differences in hand hygiene practices among college students. Am J Infect Control 2008; 36: 361-368. https://doi. org/10.1016/j.ajic.2007.09.007 
20. Taylor JK, Rasco R, Zaied A, Ward C. Hand hygiene knowledge of college students. Clin Lab Sci 2010; 33: 89-92. https://doi. org/10.29074/ascls.23.2.89

21. Zingg W, Imhof A, Maggiorini M, Stocker R, Keller E, Ruef C. Impact of a prevention strategy targeting hand hygiene and catheter care on the incidence of catheter-related bloodstream infections. Crit Care Med 2009; 3: 2167-2173. https://doi.org/10.1097/CCM.0b013e3181a02d8f

22. Aiello $A E$, Malinis $M$, Knapp JK, Mody L. The influence of knowledge, perceptions, and beliefs, on hand hygiene practices in nursing homes. Am J Infect Control 2009; 37: 164167. https://doi.org/10.1016/j.ajic.2008.04.258

23. Porzig-Drummon R, Stevenson R, Case T, Oaten M. Can the emotion of disgust be harnessed to promote hand hygiene? Soc Sci Med 2009; 68: 1006-1112. https://doi.org/10.1016/j. socscimed.2009.01.013
24. Sladek RM, Bond MJ, Phillips PA. Why don't doctors wash their hands? A correlational study of thinking styles and hand hygiene. Am J Infect Control 2008; 36: 399-406. https://doi. org/10.1016/j.ajic.2007.11.002

25. van de Mortel TF, Apostolopoulou E, Petrikkos G. A comparison of the hand hygiene knowledge, beliefs, and practices of Greek nursing and medical students. Am J Infect Control 2010; 38: 75-77. https://doi.org/10.1016/j. ajic.2009.05.006 